\title{
A Better Book on Biotech
}

\section{Daniel P. Maher}

Published online: 30 November 2010

(C) Springer Science+Business Media, LLC 2010

Yuval Levin, Imagining the Future: Science and American Democracy. New York and London: Encounter Books. 2008. 145pp. \$21.95. ISBN-10: 1594032092; ISBN-13: 978-1594032097

Sean D. Sutton, editor, Biotechnology: Our Future as Human Beings and Citizens. Albany, N.Y.: SUNY Press. 2009. 198pp. \$24.95. ISBN-10: 1438426860; ISBN-13: 978-1438426860

On the assumption that bioengineers of various kinds are going to be tinkering with the human genome, I have sometimes wished that they would produce human beings endowed with a capacity to write excellent books on the ethics and politics of biotechnology. I doubt they will come through, which leaves us with the books that appear "naturally." That this is not such a bad fate is proved by Yuval Levin, who has written a very good book without - if we are to trust his acknowledgements-performanceenhancing biotechnology. Levin's book turns on an expansion of the distinction between the influence that we exercise through a book, for example, over the thinking and acting of the next generation and the influence that we would exercise through "direct intervention in children's bodies and minds." He argues that if we abandon traditional forms of education and influence in favor of technical alteration of biological capacities, we begin to undermine the structures essential to our self-government. Levin would say I ought to write by my own hand the book I would like to see, rather than engineer someone else who could write no other.

D. P. Maher $(\bowtie)$

Department of Philosophy, Assumption College,

500 Salisbury Street,

Worcester, MA 01609, USA

e-mail: dmaher@assumption.edu
Perhaps one day authors will introduce their books by crediting their parents' genetic counselors or some technician at Amgen. Levin follows the conventional path of identifying friends and teachers, and, for enriching life beyond the book, he acknowledges his "greatest fortune" is his family. Books come and go in the grip of chance. Insightful authors appear whenever they do, and their books await an uncertain reception. Readers and books themselves are somehow "hostages to fortune." Francis Bacon used this phrase about family - to have wife and children is to give hostages to fortune-, and biotechnology is often presented to great rhetorical effect as the agent of our liberation from this worrisome situation. If we genuinely love our children, should we not use any available power to make them as good as possible, rather than expose them to the vagaries of accident and misfortune?

One theme of Levin's book is the question of whether there is greater benevolence in preparing a child or a student for achieving his own successes (while accepting the possibility of serious disappointments) or in precluding failure by designing and guaranteeing success - so far as it lies within our power. Levin encourages us to admit we do not so completely grasp the contour of the good as to permit our engineering it into children, but neither is it wholly unknown. In art, moral action, athletics, and so on, we both recognize excellence and are sometimes surprised by its shape. This consideration should induce caution against too heavy a hand in making future goods depend on today's artful interventions. Moderation is another theme and perhaps the highest goal of Levin's book.

\section{A Reading of Levin's Book}

Imagining the Future may be conventional in its origins, but it breaks conventions by the manner in which it addresses the cliché-riddled and predictably binary public 
debates about biotechnology. Levin rightly points out that in these debates the particular technique at issue is normally of secondary importance. Disputes on embryonic stem cell research sound like lightly reheated, 1980s-era arguments over fetal tissue transplantation. Levin's focal point is not science itself or even technology, but science making its appearance as a cultural phenomenon in non-scientists' lives: science "domesticated and democratized." He traces the origins of the debates (between what he calls the left and the right) about science to something more interesting than the difference between a secular, enlightened, proscience view and a religious, benighted, anti-science view. "The dispute between them ... comes down most fundamentally to two quite different ways of thinking about the future, and that difference lies at the heart of a great deal of our political life, well beyond the science debates." For Levin, the science debates provide a lens through which we can focus on America's political and moral life. The left, he says, imagines the future in terms of an anthropology of innovation, while the right imagines the future in terms of an anthropology of generations.

"To imagine the future in terms of innovation means, most fundamentally, to imagine change in terms of new ideas, and to think of life as an array of individual experiments and choices." Liberals and libertarians favor this view. "They share a faith in the processes that drive innovation and progress in a free society, and believe that impeding these processes, or even trying to control them in advance, will only make things worse." Dangers are best averted by trial and error led by personal choice left as unfettered as possible. "Those individuals most directly affected by some new innovation will be best able to judge its value, and if they find it is harmful or not worthwhile, they will reject it." Progress must not be impeded simply because some may choose badly. This logic, which informs our democracy, economy, and culture of individualism, has led to better prosperity than any alternative. "Modern science and its progeny are agents of this kind of innovation, which is possible only in an environment that nourishes experimental liberty." As a result, those who embrace this line of reasoning are adamant in defending science from political regulation.

Imagining the future in terms of generations means being concerned to preserve cultural achievements for transmission to the next generation. "The most fundamental fact of human natality has always been that human nature emerges from the womb in essentially the same general form in every generation; or, as conservatives like to put it, that human nature has no history." Education is the unending task of protecting the civilized world from the constant assault of savagery in the form of children, and the right sees certain institutions (such as the family) as permanently necessary to every human community. Other and perhaps higher projects are judged by reference to the primary need to perpetuate civilization. Those on the right assess "each innovation not only by how it might enhance or degrade their own life, but also by how it might improve or diminish the ability of our society to raise and to tend to the next generation, and by its influence on the inheritance we could leave for the future."

Levin claims that each of these ways of imagining the future offers "a rich and compelling anthropology of progress," and he treats them with a kind of evenhandedness. Each has something true, but neither is "simply right," and so they must be balanced. Levin conveys the appearance of neutrality by devoting one chapter to each way of imagining the future in its complex relations with science, and yet he does not finally stand above the two alternatives as an impartial analyst. While Levin endorses the anthropology of generations as offering "a fuller and more recognizable account of the truth of the human condition," he shows no romantic longing for the past and credibly insists on openness to innovation. By keeping our eyes on the next generation, he argues, we have a more reliable test for assessing the goodness of the new. The left's inherent defect is neglect of the fact and necessity of children. Levin's anthropology of generations points toward a recovery not of the past but of "the past's way of thinking about the future." Past generations made possible our selfgovernance, so we must preserve the same or better possibilities for coming generations.

In Levin's view, science is both essential to our wellbeing and the source of grave threats to our political institutions. The book's first chapter deftly dismantles the thesis, widely embraced, that science is morally neutral. And Levin deserves praise for penetrating and dismissing the "profound misunderstanding" that science moves too fast for ethics. He shows that since its inception, modern science was conceived and presented to the public as a moral enterprise aimed at the relief of our estate, primarily by improving health. We non-scientists so thoroughly presuppose science as our benefactor that almost no one notices that science so conceived is essentially subordinated to the service of moral goals. Levin clearly lays out much of what ensues when this oversight becomes widespread: any discussion of moral limitation on scientific research appears as an illegitimate attempt to impose idiosyncratic moral biases restricting thought and subsequent benefits to our health and welfare.

While I think Levin overstates the primacy of health for the founders of modernity, he is surely correct about its place in popular understanding. It is unfortunate he did not go on to devote attention to the fact that once science is accepted as publicly authoritative, essentially beneficial, and not touched by moral presuppositions, all moral judgments tend to appear as arbitrary prejudices. Ulti- 
mately, this creates a difficulty for Levin's principle of moderation.

Levin recognizes that science has a corrosive effect on our confidence in the truth of moral judgment, and yet he thinks reintroducing "ancient ideals and traditions" will moderate the modern scientific project. As he frames the issue, despite being a moral endeavor, science is "morally neutralizing" in the sense of "crowding out our means of moral reasoning and sources of moral authority." $\mathrm{He}$ proposes that we somehow graft ancient wisdom onto modern political forms and guide science by a richer morality capable of securing modernity's roots. Levin's analysis of the invention of modernity by people like Bacon and Descartes is, I think, insufficiently attentive to the hostility toward ancient wisdom ingredient to the moral reasoning in which Descartes enveloped science in his Discourse on the Method. That said, because contemporary political life does not embody Baconian-Cartesian principles in their purity, Levin's moderating strategy may indeed be possible in practice.

Still, the obstacles are considerable. Descartes used the standard of scientifically rigorous certainty to cut through opinions of every kind. All moral principles fell under that pressure. Descartes then offered the useful portions of his reasoning to the public in part because he thought we might have an appetite for its advantageous fruits (as distinct from the science itself), and he ironically suggested that in doing so he was obeying a moral law to benefit mankind. We seem to have taken his bait and accepted the consequences: what science establishes is true and beyond the realm of legitimate dispute; morality is a matter of opinion, but not wisdom.

Levin's confidence that we can import a traditional, moral wisdom to guide science does not fit easily into this bargain.

To understand nature takes ever-growing knowledge.

To understand man takes the wisdom of the ages.

That wisdom, as it builds, can be informed by scientific knowledge, but it can never be replaced by

it. Science is a tremendously effective and powerful means of gaining knowledge about nature, and knowledge of nature is very important. But human beings and human societies are more than mere objects of nature, and so science alone cannot suffice.

Many will interpret Levin's claim that human beings are more than objects of nature as mere opinion. Another opinion - a scientifically informed and sophisticated opinion-says the opposite. Science may be neutral to the distinction between these opinions, but Levin's opinion suggests we can know something that is undiscoverable by science. Many scientifically minded people regard that as superstition. And so when Levin speaks of supplementing science and guiding it, or even setting society's course by "that other great modern force, public opinion, itself informed by a wide array of wisdoms," we must admit that public opinion is not knowledge but a "force" and that it is informed not only by wisdom.

The tendency of science to erode moral beliefs is addressed in the last two substantive chapters of the book, which are entitled, "Science and the Left" and "Science and the Right." He presents science as threatening moral principles in different ways for each, with the left facing much more serious difficulties for its own coherence. Whereas the left comes forward as a rational, antireligious, anti-traditional movement aiming to maximize individual freedom, the right understands itself not as an alternative but a corrective. The right embraces much of the left's interest in freedom and progress, but it remedies the left's central error of failing to provide for the next generation's needs.

Levin finds two central tensions in the left's relation to science. First, modern science aims to master nature, but the left has also embraced a reverential and moralistic attachment to preserving nature, reconceived passively as "the environment." The left seems blind to the conflict between their suspicion of the powerful (nations, corporations, and the wealthy) and their embrace of the science that generates all that power. Second, science presents a challenge to the left's attachment to equality. Science "involves on the one hand a weakening of the case for human equality, and on the other a positing of ends and purposes taken to be higher and more important than equality." Levin documents the left's trouble resisting eugenic impulses both early in the twentieth century and more recently through prenatal screening. If we openly abandon attachment to equality, now exposed and discredited as mere prejudice, we fundamentally alter our political institutions.

The left aligns itself with science so closely that it often overlooks the threat science poses to its ideals. In contrast, the right recognizes science as a consistent threat and so is prone to overreact against it. Assaults on evolutionary science may make the right seem to be what the left says it is, viz., intellectually and morally warped by "ignorant theology" or "retrograde anti-rational obscurantism." Levin tries to resolve the core issue swiftly by asserting, as if it were non-problematic, that in addition to science there is a "different realm of human knowledge." "Nothing about being an American requires one ... to accept the dubious proposition that scientific knowledge is the only knowledge relevant to the question of human beginnings." Surely this is true as a claim about citizens' responsibilities, but one must admit that modern biology just is the attempt to account for life through a "purely material description" without appeal to soul. On this view, mind either is not a 
part of nature, or it is nothing but the brain. Modern science is understood in many ways, but it tends toward two poles: materialist reductionism (in which case, it flatly denies Levin's "different realm of human knowledge") or empiricism (in which case, whatever is true beyond the observable phenomena remains outside our knowledge).

Levin regards the right's occasional overreactions against science as much less significant than a second danger: the erosion of moral principles or taboos that follows upon our bringing them to light in order to defend them. Especially in bioethics, by trying to defend the sacredness or dignity of life, death, sex, birth, and the body, we expose to the harsh light of public debate intimacies that need protection with veils, shadows, or silence.

The taboo-part sacred, part unclean-is above all kept out of reach and common view. Its rationale is generally not laid out in detail. We have a sense that deep wisdom is embedded in the prohibition, but that it is better not to unravel it in public. Our most fundamental implicit moral sentiments, which guide us but are themselves best left shrouded, surround and protect our deepest taboos.

These sentiments and insights are reasonable but not fully rational. They are wise but not explicit. We can approach them with arguments but never fully contain them.

Levin appeals to Edmund Burke at some length in support of the superiority of inarticulate taboos over rational argument. Levin nonetheless recognizes that taboos are imperfect guides and insufficiently clear for setting policy in a modern democracy. As a result, conservatives must argue in favor of what the taboo protects.

The trouble is not that it is hard to do this. Very often, there are sound and serious arguments to support an old intuition, and these can be marshalled and wielded quite effectively. If something is wrong, it is wrong for a reason, and the reason can be reached by argument ... The very act of defending taboos in the public arena requires us, in a limited but highly meaningful way, to transgress them-or at least to uncover them in ways that undercut them.

Taboos are the non-rational support for rational prohibitions, and taboos are needed not because morality is not rational, but because human beings are not always rational. The effort to make what the taboo protects non-mysterious by fully bringing to light its rationality removes the taboo's power over us even though this unveiling is not an unmasking that shows there is nothing beneath the veil after all. There is a reason for the taboo, but, knowing the reason, we are no longer awed by the taboo.
Levin is normally quite clear, but an important lack of clarity emerges once one reflects on his gift for using speech to reinvigorate feelings of awe, sacredness, and even humility or shame before the realities he exposes in thoughtful speech. He says speech reduces or hinders these feelings, but his own words evoke them. He addresses reverential rhetoric to people for whom reverential silence is a nearly forgotten possibility. The tension between what he says and does raises a question about the role of reason in morality. Sometimes he presents rational argument as a poor substitute for "moral intuitions and untouchable sentiments," and sometimes he presents it as the solid core of morality, surrounded by inherently unreliable and possibly unjust moral sentiments. Again, is morality essentially reasonable (although it stands in need of support from the right kind of feelings because we are not always guided by reason), or is there necessarily a loss of innocence for those who look behind the curtain to see why something is good or bad? A friendly request for greater clarity seems in order.

Finally, I draw attention to a difficulty within his discussion of dissecting taboos and providing reasoned arguments in their place.

Strong as they are, and they can be strong indeed, arguments are finally not a fully satisfactory substitute for moral intuitions and untouchable sentiments.

In our time, on most issues and especially in the science debates, conservatives neither have nor desire to have recourse to such mysticism. And so they must argue, knowing they are doing away with the foundations of the old, and as they do so struggling to construct new foundations - shallower but hopefully firm - before the structure topples over.

The Cartesian metaphor here embodies the assumption that philosophical reason should be responsible to construct the moral order for the benefit of mankind. To assume this is to embrace modernity at its most immoderate and to abandon the possibility that nature (which is simply identifiable neither with reason nor with sentiment) provides the root of moral order.

The deepest question raised by Levin's book is, then, the character of modernity. On Levin's view, while the right emerged and exists as a reaction to the left, the left itself emerged "in response to a new set of ideas and intellectual possibilities that burst onto the European scene in the seventeenth and eighteenth centuries-ideas and possibilities that we now think of as modern scientific thought." With these words Levin suggests a merely accidental connection between modern science and modern political thought. Science emerged to serve the appetite for health and bodily goods; at about the same time, the left brought 
forward modern political forms to serve the appetite for individual freedom, and the power that came from science happened to be usefully at hand. Accordingly, he speaks of "crosspollination between the new politics and the new science" and of their being mixed together rather than of their being conceived together as parts of a single project. While Levin never makes it completely clear how he understands the relation between modern science and modern political thought, he does seem to need them to be separated for his ultimate aim of embracing modern science while moderating it with ancient wisdom.

\section{Some Light from Sutton's Book}

Many recent books assemble essays on biotechnology from multiple authors, presumably in order to overcome the narrowness of point of view that might afflict a work by a single author. Given that Descartes, modernity's architect, said he found greater perfection in works composed by a single master than in those produced by many, it is interesting that books on so quintessentially modern a topic regularly take this form. If we compare Levin's book with Biotechnology: Our Future as Human Beings and Citizens, edited by Sean D. Sutton, it is difficult not to side with Descartes and, hence, Levin.

The seven essays in Sutton's volume are drawn from a 2004 to 2005 lecture series at Rochester Institute of Technology. The contrast between Levin's unified analysis and this many-headed creature is pronounced. The authors in Sutton's book display almost no agreement as to what deserves attention, and only Richard Sherlock directly engages the other essays. Some authors do cite a 2003 paper by Leon Kass, published in New Atlantis as "Ageless Bodies, Happy Souls" and reprinted here in a slightly edited version (a fact acknowledged nowhere in this volume). In the remainder of this review, I would like to use two essays from Sutton's volume to shed further light on Levin's.

First, in "Who's Afraid of Posthumanity?"-Ronald Bailey's enthusiastic and uncritical endorsement of what he calls biotechnical miracles - we see an expression of the obstacle confronting Levin's moderating ancient wisdom. Many authors, as Levin noted, see that objections can be made in the name of equality against some biotechnology as threatening to yield a sort of biologically determined caste system. Bailey dismisses these objections as "nonsense," on the grounds that political equality does not presuppose or require "actual physical and mental equality." "The ideal of political equality arose from the Enlightenment insistence that since no one has access to absolute truth, no one has a moral right to impose his or her values and beliefs on others."
On the one hand, this sort of claim is so thoroughly commonplace that it almost seems self-evidently reasonable, and not only to the left. We are so accustomed to moral skepticism and the privatization of judgments about the good that we hardly notice the dogmatism ("insistence") embedded in such declarations. Bailey feels no need to justify the claim to know that others cannot know. Somewhere, Descartes is smiling on this perfect display of the corrosive effect of science on moral judgment. Science itself, as the standard for knowledge, seems to establish that Levin's moral knowledge does not exist.

On the other hand, it is stunning that this thesis does not strike Bailey as self-defeating, or even as questionable. In this he exhibits the pronounced thoughtlessness on moral things that ensues once we deny the existence of moral knowledge. He is not alone. Deference to science and retreat from the responsibility of moral judgment are so embedded in our lives that many fail to notice the absurdity lurking in the inference from moral skepticism to a moral prohibition. No one knows what is good or bad, and therefore it is absolutely bad to hold anything as truly good. People who embrace this view submit to moral strictures imposed by Enlightenment thinkers even as they deny the legitimacy of anyone's imposing moral strictures.

Bailey seems to withdraw all this in the next paragraph: "In any case, the ideals of democracy and political equality are sustained chiefly by the principle that people are responsible moral agents who can distinguish right from wrong and therefore deserve equal consideration before the law and a respected place in our political community." According to the thesis quoted above, our equal capacity for moral discernment could only be an equal inability to discern truthfully. Thus, what looks like an endorsement of moral thinking is actually a reassertion that no moral judgment is simply true. The prior thesis nullifies this one and preserves the distinction between objective science and merely subjective moral opinion. Levin is not unaware of Bailey or of this position, but he did not engage this obstacle directly. One need not be as hardened as Bailey to find Levin's appeals to moral knowledge a little too easy.

Second, for reasons he does not explain, Levin chose to avoid substantive consideration of religion or theology, a noticeable absence that seems more significant in view of Sutton's book. At one point, Levin refers to "the deep moral wisdom at the heart of our civilization - by which most Americans live their lives." Several authors in Sutton's volume recognize in various ways the prominence of religion or theology in our debates about morality and science, and this seems to be the one point where Sutton's collection surpasses Levin's book. To have addressed this would lengthen and complicate Levin's work, but to focus 
on America's moral and political life and, simultaneously, not to confront this dimension of our rhetorical situation is to have elided over essentials.

In "A Transcendent Vision," Richard Sherlock argues that theology is not only circumstantially relevant but indispensable to public debate on biotechnology because it alone offers a standard for judgment once we push beyond nature. "The problem for the western moral tradition is that if the claims of 'redesign' are even possible then it would appear that we can no longer rely on nature itself as a complete and sufficient basis of moral theory." When nature cannot guide, we must turn to "transnaturalism, that is, theology." Sherlock's solution is less compelling than his question: what is the moral reference point for evaluating the emergence of beings that are not human as we are? Levin argues that for conservatives and liberals the distinction between good and bad derives from conditions that would no longer obtain if we controlled the biology of our offspring. The children would be constructed according to moral principles that would not fit their being constructed. The principles come from a world where nature is fixed, and the children would inhabit a world where human nature is constructed. The attempt to use theology to remedy this difficulty should interest Levin.

\section{Conclusion}

Even in the light of these substantive difficulties, I wish to reiterate that Levin's is a very good book. He writes elegantly and insightfully on matters of substance. He demands and rewards a thoughtful consideration of his argument, which is regularly graced with suggestive formulations. One immediately recognizes the influence of his teacher Leon Kass, but Levin's book is not simply Kass recast, if you will forgive the phrase. Also, despite the fact that most of the book has appeared previously in essay form, he has structured his work here into a coherent whole. As he says in the introduction, he has written a small book on a large topic; without pretending to say everything, he aims to point toward the core. Levin has succeeded admirably in giving us much food for thought by addressing his subject at a depth most writers avoid. Finding a quarrel at this level increases rather than lessens one's appreciation of this excellent book.

Daniel Maher is Associate Professor of Philosophy at Assumption College in Worcester, Mass. His research centers on ancient Greek philosophy, especially Aristotle, and medical ethics. Recently he published "Theory in Bioethics" in Medical Ethics and Humanities (Jones \& Bartlett), edited by Paola, Walker, and Nixon. He has also published in National Catholic Bioethics Quarterly, Linacre Quarterly, and the Journal of Contemporary Law and Health Policy. 